\title{
BEEF PRODUCTION FROM LUCERNE AND LUCERNE/PRAIRIE GRASS SWARDS ON THE PUMICE SOILS OF THE TAUPO REGION
}

\author{
K. Marsh \\ Ruakura Animal Research Station, Hamillon
}

L. F. C. BRUnswick

Wairakei Research Station, Taupo

\begin{abstract}
Lucerne and lucerne/prairie grass swards were compared at threc stocking rates using yearling beef cattle. A 35-day rotational grazing system was used and the experiment ran for 130 days from early October, 1976. Pasture DM yields were higher on the mixcd sward but animal production was greater on the lucerne only sward, particularly from December onwards. Increasing stocking rate tended to reduce herbage DM yield and per-animal production. There was no significant interaction between sward type and stocking rate on either sward or animal yield. Lucerne and lucerne/ prairie grass swards on pumice soil compared favourably with fertile Waikato permanent pastures in terms of carcass gain per hectare over the grazing period.
\end{abstract}

\section{INTRODUCTION}

It is well established that lucerne (Medicago sativa) produces annually more DM per hectare on dry soils than grass/clover swards (Vartha and O'Connor, 1968). This advantage is particularly noticeable on the pumice soils of the Taupo region where Baars et al. (1975) found mean annual DM yield from a flat-land grass pasture was about $6000 \mathrm{~kg} / \mathrm{ha}$ compared with over $13000 \mathrm{~kg} \mathrm{DM} / \mathrm{ha}$ from lucerne. This is reflected in the increasing area sown to lucerne in this area (R. B. Gordon, pers. comm.).

However, little attention has been given to animals, particularly beef cattle, grazing lucerne in this region. In a hand-feeding experiment, Joyce and Brunswick (1975) found freshly harvested lucerne, supplemented with $\mathrm{NaCl}$ and offered to appetite, supported daily gains of $0.9 \mathrm{~kg}$ in yearling cattle from October to January. Although that experiment demonstrated that lucerne when cut and carted can support high rates of gain in beef cattle, this might not necessarily occur under a prolonged grazing period. 
A grazing experiment was therefore set up in 1975 to provide information of this nature for both lucerne and lucerne/prairie grass (Bromus catharticus) swards. The first year's results, when a flexible beef-leader/sheep-follower management system was employed, have been reported elsewhere (Joyce and Brunswick, 1977). This paper will deal with the second and final year's results when a fixed management policy was imposed.

\section{EXPERIMENTAL}

The experiment was carried out at the Wairakei Research Station, Taupo, from October 8, 1976, to February 15, 1977, on 9 ha divided into two topographical areas. One site, representing $52 \%$ of the total area, was on flat land. The lucerne (Medicago sativa L. cv. 'Marlborough') was sown on this area in 1962. Half was oversown with prairie grass (Bromus catharticus Vahl. cv. 'Grasslands Matua') in the autumn of 1975. The other site was on moderate to steep hill sides; the lucerne (M. sativa L. cv. 'Wairau') was established in 1972 and half was oversown with prairie grass in 1975.

The experiment was of a $3 \times 2$ factorial design and evaluated the effects of three stocking rates $(\mathrm{L}, 5.0 ; \mathrm{M}, 6.67$; and $\mathrm{H}, 10.0$ animals per hectare) and two sward types (lucerne, and lucerne/ prairie grass) on liveweight gain of cattle. Each sward type was randomized over 5 blocks on the flat land site and over 7 blocks on the hill site. These 12 blocks per sward type enabled a 35-day rotation to be imposed with not more than 7 days' grazing in any one block per cycle. Each sward type within each block was subdivided in the ratio of 4: $3: 2$ to enable the imposition of stocking rate treatments with equal numbers (1.0) of cattle per stocking rate.

Sixty-six yearlings (20 steers and 46 heifers), progeny of Pie Rouge bulls and Angus half-bred cows, were divided into 6 groups of 10 and one group of 6 on the basis of sex, fasted weight and conformation. The group of 6 was slaughtered to provide the relationship between fasted liveweight and carcass weight for predicting initial carcass weight of the 6 treatment groups of cattle. These groups were allocated to treatments at random to give the required stocking rates (see above).

The cattle grazed each block of paddocks in turn according to a predetermined rotation. Uneaten herbage was left in situ and animals always returned to their same paddocks so that cumulative effects of treatments could be determined. There was no 
back-fencing within paddocks and cattle always had access to water and salt licks.

Pre-grazing DM yields were determined in every paddock of each treatment during the first 35-day cycle by cutting to crown level and weighing random quadrats $\left(\begin{array}{ll}1 & \mathrm{~m}^{2}\end{array}\right)$ and drying subsamples at $100^{\circ} \mathrm{C}$. During the regrowth cycles (2 to 4 inclusive) pre-grazing yields were determined on only a small sample (3) of paddocks. Sub-samples were also taken from each treatment for separation into four categories: green lucerne, green prairie grass, green weeds and dead matter.

Animals were weighed unfastcd on 8 occasions. At the end of the experiment, 3 cattle from each treatment were slaughtered and carcass weights recorded. The carcass weight/unfasted liveweight relationship was used to predict mean final carcass weight of cattle on each treatment.

\section{RESULTS AND DISCUSSION}

Pre- and post-grazing DM yields and mean per-grazing utilization coefficients for first growth (cycle 1) and treatment regrowths (cycles 2 to 4 inclusive) are summarized in Table 1 . During the first cycle, stocking rate had no significant effect on pre-grazing yield, which indicates no significant carry-over effect of the previous year's treatments. However, yields were consistently higher (by 8\%) on the mixed sward, showing the advantage of prairie grass in promoting early season growth. Thereafter, mean DM yields of the mixed sward regrowths (cycles 2 to 4$)$ were $34 \%$ and significantly greater $(P<0.001)$ than those

TABLE 1: MEAN DM YIELD PRE- AND POST-GRAZING AND PERGRAZING UTILIZATION COEFFICIENTS

\begin{tabular}{|c|c|c|c|c|c|c|c|}
\hline & \multicolumn{7}{|c|}{ Treatments } \\
\hline & \multicolumn{3}{|c|}{ Lucerne } & \multicolumn{3}{|c|}{ Lucerne/Prairie } & $\begin{array}{l}\text { SE of } \\
\text { Mean }\end{array}$ \\
\hline \multicolumn{8}{|l|}{ Pre-grazing yield $(\mathrm{kg} / \mathrm{ha})$ : } \\
\hline Cycle $1 \quad(n=12)$ & 2690 & 2870 & 2870 & 2980 & 3060 & 3060 & \pm 148 \\
\hline Cycles 2-4 $(n=8)$ & 2470 & 2120 & 1830 & 3070 & 3270 & 2251 & \pm 178 \\
\hline \multicolumn{8}{|c|}{ Post-grazing yield (kg/ha) : } \\
\hline Cycle $1(n=12)$ & 1160 & 820 & 430 & 1530 & 1060 & 490 & \pm 109 \\
\hline Cycles 2-4 $(n=8)$ & 1740 & 940 & 150 & 2100 & 1480 & 380 & \pm 142 \\
\hline \multicolumn{8}{|l|}{ Per-grazing utilization $(\%)$ : } \\
\hline Cycle $1 \quad(\mathrm{n}=12)$ & 58 & 74 & 86 & 49 & 67 & 85 & \pm 3.5 \\
\hline Cycles $2-4 \quad(\mathrm{n}=8)$ & 27 & 56 & 87 & 31 & 54 & 83 & \pm 5.7 \\
\hline
\end{tabular}


of lucerne. Increasing stocking rate reduced $(P<0.001)$ yield of both sward types. Post-grazing or residual DM yields were higher $(P<0.05)$ in both periods on the mixed sward, and in both sward types these yields were reduced $(\mathrm{P}<0.001)$ by increasing stocking rate. Mean utilization per grazing was not significantly affected by sward type but was significantly increased by the higher stocking rate treatments in both periods. Utilization by the $\mathrm{H}$ stocking rate cattle was consistently high throughout the trial but on the $\mathrm{L}$ and $\mathrm{M}$ treatments utilization was lower on the regrowth than on first growth herbage. Sufficient data to estimate mean daily DM intake are only available for cycle 1 when all paddocks were sampled. Mean daily DM intakes were 8.7, 8.8, and $7.0 \mathrm{~kg}$ on the low, medium and high stocked lucerne swards, and $8.3,8.6$, and $7.3 \mathrm{~kg}$ on the low, medium and high stocked lucerne/prairie grass swards, respectively.

Treatment effects on mean botanical composition over the whole experiment are illustrated in Fig. 1. Dead dry matter content as a percentage of total DM was greater on the mixed than on the lucerne only sward, but in both swards was decreased by increasing stocking rate. Peak dead matter content was reached in both sward types in mid-January. Over the regrowth cycles 2 to 4 inclusive mean pre-grazing DM yield accounted for $94 \%$ of the variation in dead matter content between treatment means when analysed by regression; between individual paddocks $20 \%$ of the variation in dead matter content was accounted for by DM yield, indicating a build-up of dead matter following high yields of uneaten herbage. Of the green material, sown species

TABLE 2: ANIMAL PRODUCTION DATA (kg)

\begin{tabular}{|c|c|c|c|c|c|c|c|}
\hline & \multicolumn{3}{|c|}{ Lucerne } & \multicolumn{3}{|c|}{ Lucerne/Prairie } & \multirow{2}{*}{$\begin{array}{l}\text { SE of } \\
\text { Mean }\end{array}$} \\
\hline & $\mathbf{L}$ & M & $\mathbf{H}$ & $\mathbf{L}$ & M & $\mathbf{H}$ & \\
\hline Initial unfasted LW & 204.8 & 204.4 & 206.6 & 204.5 & 205.6 & 205.6 & \pm 1.77 \\
\hline $\begin{array}{l}\text { Initial fasted LW } \\
\text { Predicted initial }\end{array}$ & 191.6 & 190.5 & 191.0 & 188.9 & 190.6 & 190.9 & \pm 1.47 \\
\hline carcass weight & 99.7 & 99.2 & 99.4 & 98.6 & 99.3 & 99.4 & - \\
\hline Daily gain, cycle 1 & 1.39 & 1.28 & 1.08 & 1.41 & 1.14 & 1.09 & \pm 0.081 \\
\hline Daily gain, cycles 2-4 & 1.12 & 0.89 & 0.47 & $0: 98$ & 0.76 & 0.40 & \pm 0.047 \\
\hline $\begin{array}{l}\text { Final liveweight } \\
\text { Predicted final }\end{array}$ & 365.0 & 337.2 & 290.5 & 351.9 & 325.1 & 289.1 & \pm 6.53 \\
\hline carcass uei ght & 188.3 & 171.9 & 144.5 & 180.6 & 164.8 & 143.7 & - \\
\hline Unfasted LWG/ha. & 801 & 886 & 839 & 737 & 797 & 835 & - \\
\hline Carcass weight gain/ha & 443 & 485 & 451 & 410 & 437 & 443 & - \\
\hline
\end{tabular}




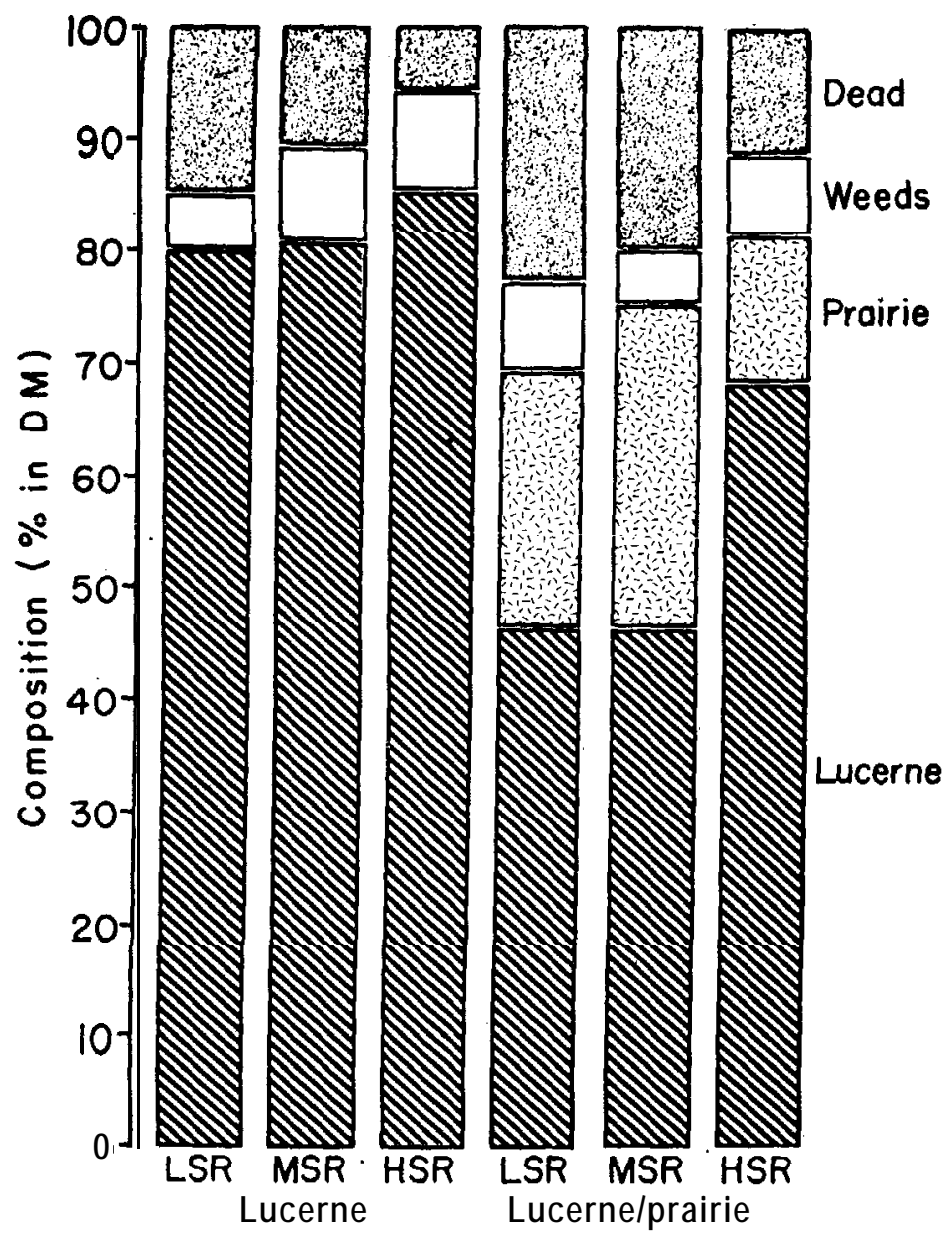

FIG. 1: Effect of sward type and stocking rate on bolanical composition.

accounted for 91 to $94 \%$ of both sward types. In the mixed swat-d, prairie grass was 33 to $38 \%$ of the sown species on the medium and low stocking rate treatments and similar to the mean figure of $31 \%$ given by Joyce and Brunswick (1977) for the previous year's trial. However, this proportion had declined to $16 \%$ on the $\mathrm{H}$ stocking rate treatment, indicating that prairie grass is not a suitable species for heavy grazing on infertile soils, which supports the statement to this effect by Rumba11 (1974) . 
Animal production data are given in Table 2 and are also divided into two periods: Period 1 is over the first cycle when animals on all treatments were making rapid gains. However, there was still a significant reduction $(P<0.01)$ in daily gain in Period 1 by increasing stocking rate but sward type had no significant effect. The high rates of gain in this first period are probably partially a result of compensatory growth following restricted winter feeding, as indicated by the low initial liveweight of $205 \mathrm{~kg}$ for 14-month-old cattle. Similar rapid rates of gain (1.3 $\mathrm{kg} /$ day approximately) were found the previous year (Joyce and Brunswick, 1977) when cattle of similar weight for age were used.

During cycles 2 to 4 inclusive mean daily growth rate of cattle on the mixed sward was consistently lower $(P<0.01)$ than that of cattle grazing lucerne $(0.71 \mathrm{us} .0 .83 \mathrm{~kg})$. This occurred despite the greater yield of pasture DM available on the mixed sward at each stocking rate (Table 1) and this is probably related to a herbage quality effect which, as indicated by the significant correlation between yield and dead matter content, was lower in the mixed than on the pure lucerne swards. This suggestion is further supported by modified-acid-detergent (MAD) fibre (Clancy and Wilson, 1966) contents of samples of pre-grazed herbage DM which were higher $(33.4 \%)$ in the mixed than in the lucerne only swards (29.4\%). MAD fibre content of pre-grazed lucerne DM during cycles 2 to 4 inclusive was reduced from 33.2 to $27.3 \%$ and of lucerne/prairie grass DM from 34.6 to $31.6 \%$ by increasing stocking rate to 10 animals per hectare.

The effect of increasing stocking rate on reducing rate of liveweight gain during cycles 2 to 4 was highly significant $(P<$ 0.001). On the $\mathrm{L}$ treatment (5 animals/ha) gains were high, indicating little, if any, restriction in performance and therefore wasteful of the herbage DM available, as indicated by the buildup of dead matter, high refusal yields, and low coefficients of utilization (Table 1). Doubling the stocking rate $(\mathrm{H})$ to 10 animals/ha increased utilization of available pasture to about $85 \%$ but reduced daily liveweight gains to less than $0.5 \mathrm{~kg}$ on both sward types which is too low if slaughter at reasonable weights before 2 years of age is to be attempted. The rate of gain on the $M$ treatment (6.67 animals/ha! was intermediate and this stocking rate is therefore probably close to the optimal for this class of stock on lucerne swards in this area. This suggestion is supported by the levels of carcass gain per hectare 
(Table 2), which were highest on the $M$ treatment on the lucerne only sward, and only $6 \mathrm{~kg}$ less than those produced on the highest stocking rate on the mixed sward. These carcass yields, of about $450 \mathrm{~kg} / \mathrm{ha}$, represent about $3.5 \mathrm{~kg}$ carcass/ha/day of grazing which compare well with potential levels of carcass yield from intensive lowland pastures (Marsh, 1977).

Over the 130-day trial, the mean effect of introducing prairie grass into established lucerne stands was not significant, which agrees with the previous year's finding (Joyce and Brunswick, 1977). This lack of a substantial increase in summer beef production does not necessarily negate oversowing this species into lucerne, as the primary reason for doing this is to increase herbage yields during the cooler winter-spring period when DM requirements by, for example, pregnant and lactating ewes or dairy cows are high and lucerne production is low.

\section{ACKNOWLEDGEMENTS}

We wish to thank the staff of the Wairakei Research Station, particularly J. A. Roderick, for assistance in running the experiment, the staff of the Dissection Laboratory at Rukuhia for the botanical analysis, and K. E. Jury for advice on statistical matters.

\section{REFERENCES}

Baars, J. A.; Radcliffe, J. E.; Brunswick, L. F. C., 1975. N.Z. /l exp. A gric., 3: $253-8$

Clancy, M. J.; Wilson: R. K., 1966. Proc. 10th int. Grassld Congr., Helsinki: $445-53$.

Joyce, J. P.; Brunswick, L. F. C., 1975. Proc. Ruakura Fmrs' Conf.: 35-8,

- $;$ 1977. Proc. N.Z. Soe. Anim. Prod., 37: 67-71.

Marsh, R., 1977. Proc. N.Z. Soc. Anirn. Prod., 37: 62-6.

Rumball, W., 1974. N.Z. $/ /$ exp. Agric., 2: 1-5.

Vartha, E. W.; O'Connor, K. F., 1968. Proc. N.Z. Soc. Anirn. Prod., 28: 65-73. 